\title{
172. Spectrometric Studies on the Catalase in Acatalasemic Red Blood Cell Extracts, Stages 2 and 3 by Herbert-Pinsent
}

\author{
By Shigeo TAKAharA*) and Masana OGATA \\ Okayama University Medical School, Okayama \\ (Comm. by T. Furuhata, M.J.A., Dec. 12, 1962)
}

Introduction. With respect to the presence or absence of catalase protein itself, we already proved by paper electrophoretic ${ }^{1)}$ and immunological ${ }^{2)}$ methods that catalase protein is absent in acatalasemia $^{3)-7)}$ while it is one half of the normal in hypocatalasemia. ${ }^{8) 9}$ This seems to indicate the lack of active catalase molecules, but it is desirable to ascertain definitely whether or not there exist such catalase molecules in acatalasemia. For this purpose spectrometric method is thought to be the only and most suitable one.

For an example, the spectrometric method has been widely employed with satisfactory results for the assay of one of heme proteins, cytochrome $\mathrm{C}^{\left.10111{ }^{12}\right)}$ in tissue. Therefore, we employed this spectrometric method for determining the presence or absence of catalase molecules in the acatalasemic blood extracts, stages 2 and 3 by HerbertPinsent.

Materials. The heparinized blood taken from the cubital vein of normal and acatalasemic individuals was used.

Methods. The method used for catalase purification was essentially the same as described by Herbert and Pinsent. ${ }^{13)}$ The red blood cells were separated from $15 \mathrm{ml}$ of heparinized human blood by centrifugation and washed three times with 0.9 per cent physiological saline solution, and then an equal volume of distilled water was added to the cell solution (stage 1). This cell suspension was treated with ethanol-chloroform 3:1 mixture, in volume ratio of the cell suspension to the ethanol-chloroform mixture, 1:0.44, and stirred for 15 minutes.

The precipitated hemoglobin was discarded by centrifugation and the supernatant (stage 2 solution) thus obtained was divided into two parts. One part was dialyzed against physiological saline solution to be used for spectrophotometric experiment. The other was treated with suspension of $\mathrm{Ca}_{3}\left(\mathrm{PO}_{4}\right)_{2}$-gel prepared according to the method of Keilin and Hartree. ${ }^{14)}$ After centrifugation, the precipitate con-

*) Department of Oto-Rhino-Laryngology.

**) Department of Public Health.

This work was supported by a grant-in-aid by the Rockefeller Foundation (RF 60102). 
taining catalase activity was shaken vigorously with the mixed solution of 0.5 moles potassium oxalate and 0.5 moles $\mathrm{NaH}_{2} \mathrm{PO}_{4}$ solution. The calcium oxalate produced by this procedure was precipitated by centrifugation and discarded. The supernatant (stage 3 solution) obtained in this way containing catalase activity was dialyzed against physiological saline solution in a refrigerator over-night, and this dialysate, proving its Kat. $f$ to be 8,000 by Euler's method, ${ }^{15}$ was used for this spectrophotometric experiment.

Stage 5 solution was obtained by the use of ammonium sulfate from the stage 4 solution. These samples, stage 2,3 , and 5 solutions, were adjusted to $\mathrm{pH} 6.8$, by diluting with two volumes of 0.2 moles phosphate buffer and used for spectrophotometric measurement. All analysis was carried out by a Beckman DU-2 spectrophotometer with automatic recorder.

Results. Absorption Spectra of Stage 5 Solution. Fig. 1-A shows the absorption spectrum of purified catalase solution (stage 5) obtained from normal subject and it shows three absorption bands centered at 505,520 , and $625 \mathrm{~m} \mu$, which coincide with the absorption bands of the crystalline red blood cell catalase reported by Herbert and Pinsent. ${ }^{13)}$

Absorption Spectra of Stage 2 Solution. Fig. 1-B shows the absorption spectra of crude catalase solution (stage 2) from normal red blood cells, and it has the same three absorption bands as stage 5 . In acatalasemic blood there can be hardly seen any absorption band

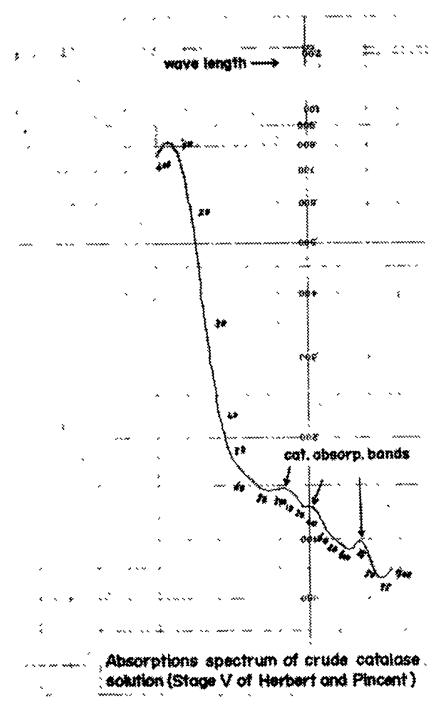

Fig. 1-A. Absorption spectrum of crude catalase solution (stage 5 by Herbert-Pinsent).

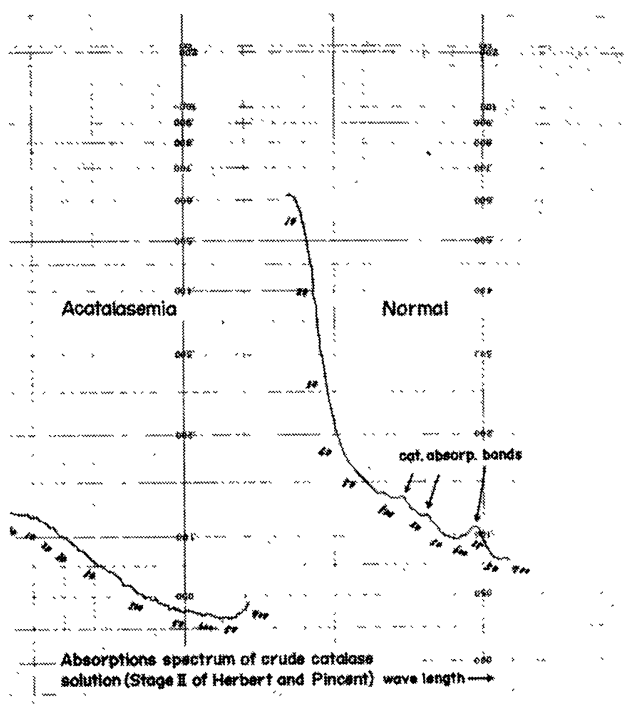

Fig. 1-B. Absorption spectra of crude catalase solutions (stage 2). 


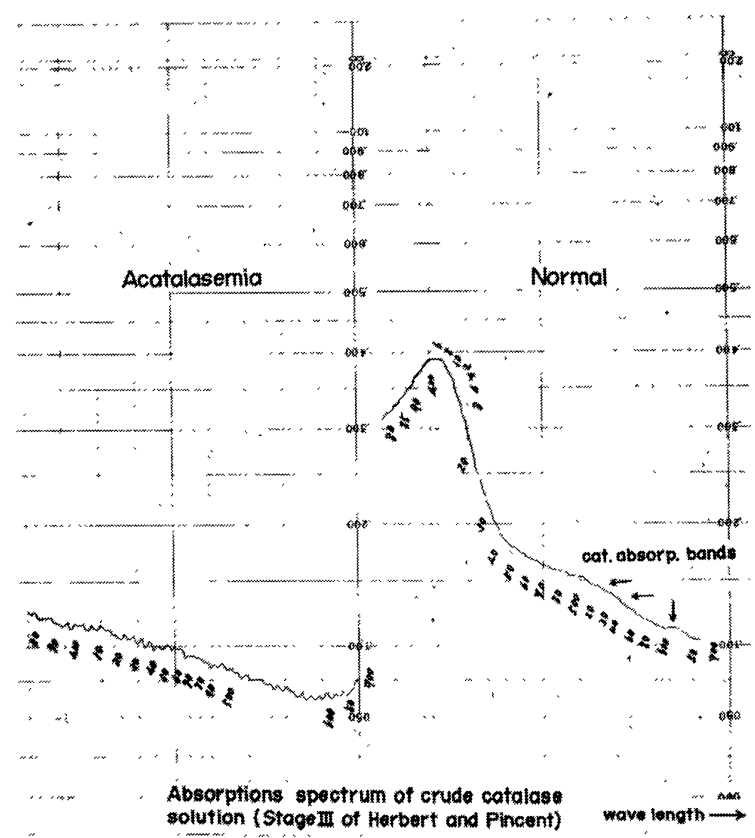

Fig. 2. Absorption spectra of crude catalase solutions (stage 3 ).

of catalase.

Absorption Spectra of Stage 3 Solution. Fig. 2 illustrates the absorption spectra of crude catalase solutions (stage 3) obtained from normal and acatalasemic red blood cells. Normal extract (stage 3) has three maximum absorption bands, but their peaks of catalase protein are lower than those of stage 2. This seems to be due to the lower catalase concentration in stage 3 than that of stage 2 , because probably a portion of catalase is lost in the preparation processes from stage 2 to 3 . Fig. 2 also shows the absorption spectra of extract obtained from acatalasemic blood and in this case acatalasemic extract shows no catalase absorption bands.

From the above results it is concluded that there are no catalase molecules in the extracts of stages 2 and 3 , of acatalasemic red blood cells.

Discussion. With the purpose to know the presence or absence of catalase protein in acatalasemic blood, already we have conducted several studies from various angles as follows:

1. We found that the extracts (stages 2 and 3 by HerbertPinsent) of acatalasemic blood did not react with catalase antibody. From these immunological studies it can be said that the catalase protein is lacking in these extracts. 
2. In the paper electrophoresis of stage 3 extract of acatalasemic blood, no catalase peak could be recognized at all. This fact further confirms the absence of catalase protein as stated in the immunological studies. In this experiment of paper electrophoresis we observed brown coloration at the catalase position in stage 3 extract of normal blood before staining with brom-phenol-blue, but in the stage 3 extract of acatalasemic blood we did not see it. As the brown coloration itself means the existence of catalase molecules, these results suggest that catalase molecules themselves are absent in acatalasemic blood.

3. In our spectrometric study our belief mentioned above has been further confirmed from the fact that acatalasemic blood extracts (stages 2 and 3) did not show any absorption bands of catalase as to indicate the lack of catalase molecules themselves in these extracts.

Conclusion. 1. In the absorption spectra of crude catalase solutions (stages 2, 3, and 5) of normal blood, three absorption bands, characterizing catalase molecules, are recognized.

2. Three catalase absorption bands cannot be found in acatalasemic blood extracts (stages 2 and 3 ).

3. It is inferred that catalase molecules themselves do not exist in the crude catalase extract from acatalasemic red blood cells.

Acknowledgement. We want to thank the late Prof. K. Ohtahara, Department of Public Health, for his valuable suggestions during this work.

\section{References}

1) Ogata, M. and Takahara, S.: Proc. Japan Acad., 38, 361 (1962).

2) Takahara, S., Ogata, M., Kobara, T. Y., Nishimura, E. T. and Brown W. J.: Lab. Invest., 11, 782 (1962).

3) Takahara, S., and Miyamoto, H.: Nihon Jibi Inkoka Gakkai Kaiho (J. Otorhinolaryngological Soc. Japan) (in Japanese), 51, 163 (1948).

4) Takahara, S., and Miyamoto, H.: Jibiinkoka (in Japanese), 21, 53 (1949).

5) Takahara, S., Mihara, S., Tsugawa, K. and Doi, M.: Proc. Japan Acad., 28, 383 (1952).

6) Takahara, S.: Lancet, 2, 1101 (1952).

7) Takahara, S.: Proc. Japan Acad., 27, 295 (1951).

8) Takahara, S., Hamilton, H. B., Neel, J. V., Kobara, T. Y., Ogura, Y. and Nishimura, E. T.: J. Clin. Invest., 39, 610 (1960).

9) Nishimura, E. T., Hamilton, H. B., Kobara, T. Y., Takahara, S., Ogura. Y. and Doi, K.: Science, 130, 333 (1959).

10) Potter, V. B., and Dubois, K. P.: J. Biol. Chem., 142, 417 (1942).

11) Elliot, K. A. C., and Keilin, D.: Proc. Roy. Soc., 114, 210 (1934).

12) Chance, B.: Science, 120, 767 (1954).

13) Herbert, D., and Pinsent, J.: Biochem. J., 43, 203 (1948).

14) Keilin, D., and Hartree, E. F.: Proc. Roy. Soc., 124, 397 (1938).

15) von Euler, H., and Josephson, K.: Justus Liebigs, Ann. Chem., 452, 158 (1927). 